\title{
Posterior Superior Iliac Spine
}

National Cancer Institute

\section{Source}

National Cancer Institute. Posterior Superior Iliac Spine. NCI Thesaurus. Code C139206.

A bony projection from the posterior region of the iliac crest that lies over the sacroiliac joint and functions as the site of attachment for the thoracolumbar fascia and the posterior sacroiliac and sacrotuberous ligaments. 